\title{
TRATAMENTO DE EFLUENTES DA FABRICAÇÃO DE NITROCELULOSE - SCALE UP
}

\author{
L. F. SANTOS ${ }^{1}$, T.C.B.PAIVA ${ }^{2}$ e F.T. SILVA $^{2}$
}

Escola de Engenharia de Lorena - USP, ${ }^{1}$ Departamento de Química e ${ }^{2}$ Departamento de Biotecnologia

E-mail para contato: professorlucrecio@usp.br ou lucreciofabio@gmail.com

\begin{abstract}
RESUMO - As principais etapas de fabricação da nitrocelulose são: deslignificação do algodão, branqueamento do algodão deslignificado e nitração da celulose. Tais etapas geram efluentes que, se não tratados, podem contaminar o meio ambiente. O efluente da deslignificação (licor negro) foi caracterizado antes e após tratamento, cujo tratamento consistiu na combinação de um processo químico, seguido de biológico. O tratamento químico foi realizado em reator de 200 L e aproveitou o efluente ácido da etapa de nitração para acidificação do licor negro, na proporção de 4:1, o que possibilitou a redução de cor em $96 \%$, COT em $94 \%$, DQO em $88 \%$ e DBO em $92 \%$. Após o tratamento químico, o efluente foi submetido ao processo biológico com lodo ativado, em reatores de $50 \mathrm{~L}$ e $500 \mathrm{~L}$. Considerando a caracterização inicial do licor negro, após o tratamento biológico, obteve-se a redução de cor em 94\%, COT em 97\%, DQO em 96\% e DBO em 99\% e a toxicidade frente a Artemia salina, na concentração analisada, foi eliminada totalmente. Os resultados mostram que o tratamento combinado: químico seguido de biológico, possibilitou o enquadramento do efluente aos padrões preconizados pelo CONAMA 357/05.
\end{abstract}

Palavras-chaves: Efluente. Lodo Ativado. Nitrocelulose.

\section{INTRODUÇÃO}

A humanidade tem causado grandes impactos nos ecossistemas aquáticos por conta de lançamentos de rejeitos, tratados inadequadamente e até mesmo sem tratamento. Tais lançamentos contaminam e reduzem sobremaneira a oferta de água de fácil captação e tratabilidade. São constantes as notícias sobre a contaminação de rios e mares por diversos tipos de rejeitos, os quais causam a morte de peixes e de outros organismos aquáticos.

Em que pese a poluição ambiental ser uma preocupação global, as contaminações continuam acontecendo, principalmente porque grande parte dos processos produtivos das indústrias, como papel-celulose, farmacêutica, têxtil, agropecuária, petroquímica, siderúrgica e cosméticos são intrinsecamente poluentes (Mackenzie e David, 1991; Paiva, 1999). Além desses setores, indústrias que processam algodão para obtenção de nitrocelulose também 
geram resíduos que, se não tratados adequadamente, contribuem para o aumento da poluição (Santos, 2001). Logo, este trabalho versa sobre o tratamento do licor negro, efluente oriundo da etapa de deslignificação do algodão para obtenção da nitrocelulose, utilizando combinação de processos: químico (acidificação), seguido de biológico com lodo ativado.

\subsection{Produção de Nitrocelulose}

Segundo Fengel e Wegener (1989), a celulose consiste de unidades anidroglucopiranosídicas associadas entre si, formando um polímero linear de glicose, mantido por ligações $\beta$ - $(1 \rightarrow 4)$. As unidades de glicose adjacentes são ligadas entre si pela eliminação de uma molécula de água proveniente das hidroxilas ligadas ao carbono 1 e ao carbono 4. A posição $\beta$ do grupo $\mathrm{OH}$ requer um giro da unidade de glicose em torno do eixo $\mathrm{C}_{1}-\mathrm{C}_{4}$ do anel piranosídico. A unidade repetitiva da cadeia da celulose é a celobiose, comprimento $1,03 \mathrm{~nm}$, conforme mostra a Figura 1.

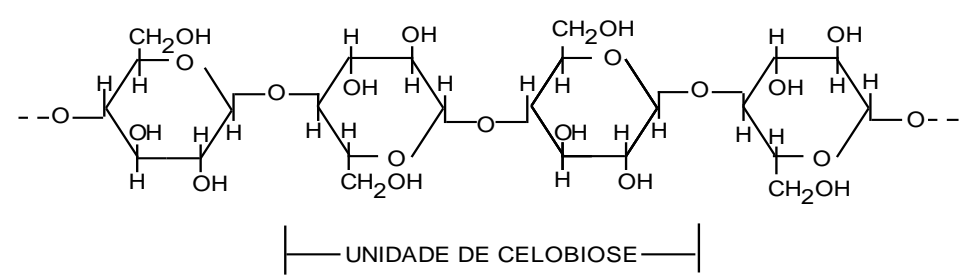

Figura 1 - Estrutura da celulose. Parte central da cadeia molecular.

Ao submeter a celulose a tratamentos químicos especificos, obtêm-se compostos com características novas e peculiares, entre eles a nitrocelulose (Temming et al., 1973).

A Fábrica Presidente Vargas, Filial 1 da Indústria de Material Bélico do Brasil, produz a nitrocelulose, cujo processo envolve várias etapas: separação mecânica do algodão, deslignificação do algodão, branqueamento do algodão deslignificado, nitração da celulose e estabilização da nitrocelulose.

A etapa de deslignificação gera um efluente rico em lignina (licor negro), que contém grupos hidroxil, formados através do ataque nucleofílico dos grupos $\mathrm{OH}^{-}$à molécula de lignina. A clivagem das ligações éter $\beta$-O-4 é responsável pela despolimerização e solubilização da lignina. Gierer (1982) propôs um modelo desta clivagem, conforme mostra Figura 2. 


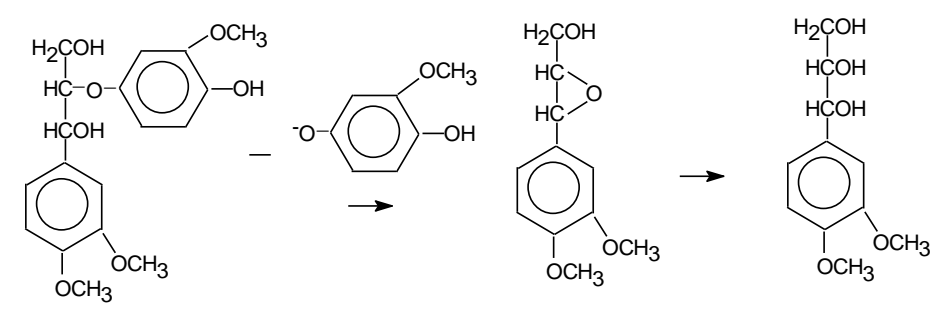

Figura 2 - Clivagem da ligação éter $\beta$-O-4 de composto modelo, gerando um epóxido e posteriormente um arilglicerol.

Após a deslignificação da polpa, uma pequena quantidade de lignina e outras impurezas como íons metálicos, compostos fenólicos, resinas e outros compostos, contendo grupos cromóforos, oriundos do material lignocelulósico, ainda, permanecem oclusos na celulose. A lignina remanescente é responsável pela tonalidade marrom-amarelada que a polpa apresenta, cuja remoção, não só da lignina residual, como também de outras impurezas se faz necessária para que se obtenha uma celulose com alto grau de alvura e pureza adequadas à etapa de nitração. Esta etapas gera um efluente que apresenta elevada cor, altos valores de DQO e DBO (Santos, 2001).

Segundo Amaral (2013), efluentes de indústria de lignocelulósicos também são caracterizados pela elevada toxicidade, causada por compostos como clorofenóis, cloroligninas, ácidos orgânicos, resinas ácidas, dioxinas e seus derivados.

O processo de branqueamento visa a remoção das impurezas remanescentes da etapa de deslignificação, entretanto, ocorrem reações de oxidação e degradação da lignina, as quais são mais difíceis de investigar do que as que ocorrem durante a polpação, por duas razões: na maioria dos casos, a estrutura da lignina residual não é conhecida; e, no branqueamento, são usados reagentes de natureza química distinta que agem simultânea ou sucessivamente (D'Almeida et al., 1988; Gierer, 1982).

Quando é usado cloro $\left(\mathrm{Cl}_{2}\right)$ ou hipoclorito de sódio $(\mathrm{NaClO})$, nas etapas de branqueamento convencional da polpa, são produzidos efluentes que contêm fragmentos de lignina modificados por esses agentes branqueadores, resultando na formação de compostos organoclorados de baixa e alta massa molar (> 1000), os quais são de difícil caracterização e degradação (Heimburger et al., 1990).

Efluentes que apresentam tais características requerem um tratamento adequado para posterior lançamento no corpo receptor.

\subsection{Tratamento de efluentes}

Segundo Sant'Anna (2013), a remoção dos poluentes no tratamento de efluentes, de forma a adequar o lançamento à qualidade desejada ou padrão de qualidade vigente, está associada aos conceitos de nível e eficiência de tratamento. São vários os tratamentos existentes, dentre eles citam-se o químico e biológico.

Os tratamentos químicos são métodos nos quais a remoção ou conversão de contaminantes ocorre pela adição de produtos químicos ou devido a reações químicas: como exemplos a precipitação e oxidação. A precipitação química se dá pela adição de um reagente capaz de, em contato com o material que se deseja precipitar, reagir e formar um precipitado 
estável de fácil remoção, melhorando a qualidade do efluente final. Os de oxidação se caracterizam por transformar a matéria orgânica em dióxido de carbono, água e íons inorgânicos, por meio de reações de degradação que envolvem espécies transitórias oxidantes, especialmente os radicais hidroxila (Teixeira e Jardim, 2004).

Os tratamentos biológicos são métodos nos quais a remoção de contaminantes ocorre por meio de atividade biológica, que reproduzem, de certo modo, os processos naturais que ocorrem no corpo d'água após o lançamento de despejo, cuja matéria orgânica é convertida à substâncias mineralizadas inertes, por mecanismos naturais, caracterizando o, chamado fenômeno da autodepuração. O mais comum e amplamente utilizado é o processo de lodo ativado (Sant'Anna, 2013).

Segundo Bento et al. (2005), o processo de lodos ativados consiste na manutenção de uma massa ativa de organismos diversificada que, em presença de oxigênio, é capaz de estabilizar a matéria orgânica presente nos despejos líquidos, onde ocorre, inicialmente, a remoção dos sólidos coloidais e dos sólidos em suspensão por aglomeração física, floculação e por adsorção dentro dos flocos biológicos. Em seguida, a matéria orgânica é, então, decomposta por processo de oxidação biológica, transformando-se em $\mathrm{CO}_{2}, \mathrm{H}_{2} \mathrm{O}, \mathrm{NH}_{3}$, novos organismos, energia e outros produtos.

Assim, este trabalho apresenta os resultados da caracterização e do tratamento do licor negro, gerado a partir das etapas de produção de nitrocelulose: deslignificação do algodão de segundo corte, visando adequá-lo para lançamento no corpo receptor. Para tanto foi realizada a sua caracterização química, biológica e ensaios de toxicidade, antes e após os tratamentos.

\section{MATERIAIS E MÉTODOS}

Esta etapa consistiu da coleta, caracterização, tratamento químico e biológico do efluente do processo de deslignificação do algodão: licor negro (Santos, 2006).

Coleta das amostras: O licor negro foi coletado em sua condição mais crítica, concentrado, durante o processo de deslignificação do algodão, e o efluente de nitração durante a etapa de nitração da celulose. Ambos foram estocados a - $4^{\circ} \mathrm{C}$ (Garcia, et al., 1987).

Caracterização: Os efluentes foram analisados em $\mathrm{pH}$; concentração de sólidos, compostos inorgânicos, compostos orgânicos, cor, COT, DQO, DBO e toxicidade, antes e depois de tratados. Foram utilizados métodos específicos da IMBEL/FPV e técnicas convencionais de análise de águas residuárias (APHA, 1992).

A toxicidade aguda dos efluentes, antes e depois de tratados, foi determinada no Laboratório de Química Biológica do Instituto de Química da UNICAMP, de acordo com a metodologia descrita por Hartl e Humpf (2000). A toxicidade frente ao microcrustáceo Artemia salina foi determinada pela porcentagem de organismos mortos em relação ao seu número inicial, na presença dos efluentes, em duas concentrações.

Tratamento químico: O licor negro foi acidificado com o efluente ácido da etapa de nitração, onde o $\mathrm{pH}$ da mistura variou de $1,5 \pm 0,3$. Para atingir tal $\mathrm{pH}$, foram adicionados $140 \mathrm{~L}$ 
do efluente de nitração $(\mathrm{pH}=1,1 \pm 0,2)$ em $35 \mathrm{~L}$ de licor negro $(\mathrm{pH}=12,4 \pm 0,2)$, na proporção de 4:1. O monitoramento de $\mathrm{pH}$ foi realizado com pHmetro da marca MICRONAL, mod. B374. Após completa floculação e precipitação de grande parte do material orgânico presente na mistura ( 2 horas), o sobrenadante (efluente tratado quimicamente) foi separado e o $\mathrm{pH}$ corrigido para 6,3 \pm 0,2 e, então, submetido ao tratamento com lodos ativados (Santos, 2006).

Tratamento biológico: Os experimentos foram realizados em duas etapas: na primeira foi utilizado um reator semicontinuo, confeccionado em PVC, de $50 \mathrm{~L}$ e volume útil de $40 \mathrm{~L}$, provido de três válvulas de drenagem, suprimento de ar $\left(>2 \mathrm{mg} \cdot \mathrm{L}^{-1}\right)$ e agitação $(175 \pm 5 \mathrm{rpm})$; na segunda foi utilizado um reator com as características do primeiro, contudo, confeccionado em aço inox, com capacidade para $500 \mathrm{~L}$ e com volume útil de $400 \mathrm{~L}$. O lodo, para dar início ao tratamento, foi cedido pela industria de papel Kimberly Clark Brasil - KCB (Santos, 2006).

\section{RESULTADOS E DISCUSSÃO}

São apresentados na Tabela 1 os resultados da caracterização do licor negro bruto e após os tratamentos químico, em reator de $200 \mathrm{~L}$, e biológico, com lodos ativados, em reator de 500L, cuja campanha de tratamento durou em torno de 6,5 meses.

Tabela 1 - Caracterização do efluente da polpação alcalina, antes e após os tratamentos químico e biológico (Valores médios \pm desvio padrão; $n=3$ )

\begin{tabular}{|c|c|c|c|}
\hline Parâmetros & $\begin{array}{c}\text { Antes } \\
\text { (Efluente bruto) }\end{array}$ & $\begin{array}{c}\text { Após tratamento } \\
\text { químico }\end{array}$ & $\begin{array}{c}\text { Após tratamento } \\
\text { biológico }\end{array}$ \\
\hline $\mathrm{pH}$ & $12,4 \pm 0,2$ & $1,5 \pm 0,3$ & $7,5 \pm 0,3$ \\
\hline Cor (UC) & $28.530 \pm 48$ & $1.159 \pm 21$ & $1743 \pm 270$ \\
\hline DQO (mg.L $\left.{ }^{-1}\right)$ & $7.797 \pm 58$ & $914 \pm 38$ & $287 \pm 11$ \\
\hline $\mathrm{DBO}\left(\mathrm{mg} \cdot \mathrm{L}^{-1}\right)$ & $4.389 \pm 129$ & $359 \pm 48$ & $38 \pm 4$ \\
\hline $\operatorname{COT}\left(\mathrm{mg} \cdot \mathrm{L}^{-1}\right)$ & $2.455 \pm 45$ & $153 \pm 3$ & $74 \pm 3$ \\
\hline $\mathrm{ST}\left(\mathrm{mg} \cdot \mathrm{L}^{-1}\right)$ & $9.269 \pm 286$ & $3.541 \pm 33$ & $296 \pm 17$ \\
\hline $\operatorname{STF}\left(\mathrm{mg} . \mathrm{L}^{-1}\right)$ & $4.035 \pm 128$ & $1.464 \pm 43$ & $180 \pm 23$ \\
\hline $\operatorname{STV}\left(\mathrm{mg}^{-L^{-1}}\right)$ & $5.234 \pm 158$ & $2.077 \pm 61$ & $116 \pm 15$ \\
\hline Nitrogênio $\left(\mathrm{mg} \cdot \mathrm{L}^{-1}\right)$ & $27 \pm 1$ & $1,6 \pm \overline{0}, 2$ & $4,3 \pm 1,8$ \\
\hline Fósforo $\left(\mathrm{mg} . \mathrm{L}^{-1}\right)$ & $<\overline{5}$ & $<5$ & $<5$ \\
\hline
\end{tabular}

O tratamento químico proporcionou a redução de DQO em $88 \%$, de DBO em $92 \%$, de COT em 94\%, de ST em 62\%, de STF em 64\%, de STV em 60\% e de, nitrogênio em 94\%. O teor de fósforo apresentou valores abaixo de $5 \mathrm{mg} . \mathrm{L}^{-1} \mathrm{em}$ todas as análises realizadas, o que pode ser justificado pela ausência de esgoto doméstico no efluente industrial. Altas concentrações de nitrogênio e fósforo no efluente podem, segundo Ribeiro (2008), causar a eutrofização. A cor foi reduzida em 96\%, indicando que grande parte dos compostos cromóforos foi removida por este tratamento, cuja comparação da redução de cor é mostrada na Figura 3. Estes resultados ratificam o que Santos (2001) obteve tratando o mesmo tipo de efluente. 


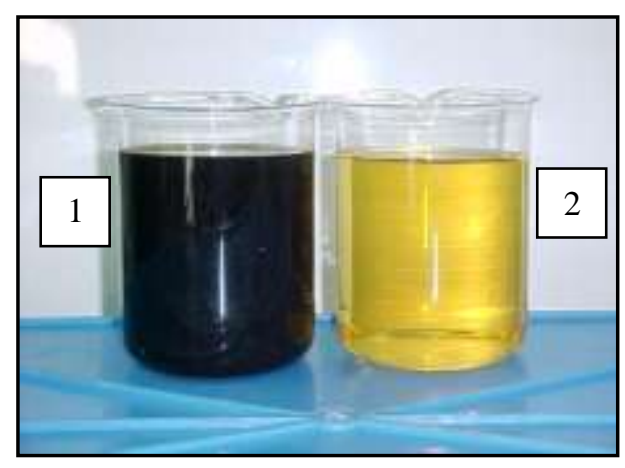

Figura 3 - Efluente: 1) antes do tratamento e 2) após tratamento químico.

Com relação à toxicidade, nas concentrações de $6 \%$ e $10 \%$, o tratamento químico não foi eficiente para reduzí-la, sendo que a imobilidade da $E$. coli foi de 16 e 50\%, respectivamente. Ribeiro (2008), ao testar o licor negro, com diluição de $50 \%$, frente à $D$. Similis, obteve $100 \%$ de imobilidade deste microrganismo, o que mostra que esse efluente realmente necessita de um tratamento adequado para posterior lançamento. Na concentração de $2 \%$ não foi observada toxicidade no efluente final, porém é uma concentração muito baixa de efluente (Santos, 2006).

Tomando por base o tratamento químico, o tratamento com lodo ativado possibilitou reduzir a DQO em 68\%, DBO em 89\%, COT em 52\%, ST em 92\%, STF em 88\% e STV em $94 \%$. Com relação ao nitrogênio ocorreu um acréscimo de $63 \%$, justificado pela adição de nutriente adicionado ao reator biológico. Após o tratamento biológico, não foi observado algum grau de toxicidade nas concentrações avaliadas (30\% e 60\%), indicando que nestas concentrações o tratamento foi eficiente. A DBO $\left(38 \mathrm{mg} . \mathrm{L}^{-1}\right)$ está de acordo com padrão de lançamento estabelecido pela legislação. A cor aumentou em 33\%, o que, segundo Mounteer et al. (2002), pode ser provocado pela pouca remoção dos compostos de baixa massa molar e pela formação de novos grupos cromóforos durante o tratamento.

\section{CONCLUSÕES}

Embora o tratamento químico tenha promovido reduções significativas em cor, COT, DQO, DBO, não foi eficaz para reduzir totalmente a toxicidade. A redução total da toxicidade só foi possível com a combinação dos processos: químico, seguido de biológico.

O efluente de nitração da celulose apresentou baixos valores de DBO, DQO e COT. Porém, seu $\mathrm{pH}$ é extremamente ácido, fora da faixa preconizada pela legislação. Essa característica possibilitou sua utilização para acidificação do licor negro, visando à precipitação da lignina, o que, além de permitir o reuso possibilitou reduzir os gastos com seu tratamento.

Este trabalho serviu de base para a elaboração de um projeto de estação de tratamento químico, com capacidade de $40 \mathrm{~m}^{3} / \mathrm{h}$, que foi executada, e elaboração de um projeto de estação por lodos ativados, com capacidade para $250 \mathrm{~m}^{3} / \mathrm{h}$. 


\section{REFERÊNCIAS BIBLIOGRÁFICAS}

AMARAL, M. C. S.; ANDRADE, L. H.; LANGE, L. C.; Borges, C. P., Avaliação da biotratabilidade do efluente de branqueamento de polpa celulósica por processos aeróbios e anaeróbios. Eng. Sanit. Ambient. v.18. n 3. jul/set. p. 253-262. 2013.

APHA - AMERICAN PUBLIC HEALTH ASSOCIATION AMERICAN WATER WORKS ASSOCIATION (AWWA), WATER ENVIROMENTAL FEDERATION (WEF), Standard Methods for the Examination of Water and Wastewater. 18 ed. American Public Health Association. Washington. 1992.

BENTO, A.P.; SEVERINO, P.H.; PHILIPPI, L.S.; REGINATTO, V.; LAPOLLI, F.R. Caracterização da microfauna em estações de tratamento de esgotos do tipo lodos ativados: um instrumento de avaliação e controle. Engenharia Sanitária e Ambiental. vol. 10 - n 4. p 329 - 338. out./dez. 2005.

D'ALMEIDA, M.L.O.; PHILIPP, P.; BARSI, D. et al. Tecnologia de Fabricação de Pastas Celulósicas. Instituto de Pesquisas Tecnológicas (IPT). 2 ed. São Paulo: v.1. p. 169 - 319 e v. 2. p. $427-509.1988$.

FENGEL, D.; WEGENER, G. Wood: Chemistry: Ultrastructure and Reactions. Walter de Gruyter. 2 ed. Berlin: 613 p. 1989.

GARCIA, E.A.; CAMARGO, A.P.F.; LUTTEMBARCK, B.H.B.; DENISE, N.P.; IVAN, R.H. Guia de Coleta e Preservação de Amostras de Água. CETESB. São Paulo: 150 p. 1987.

GIERER, J. The Chemistry of Delignification. Part 2. Holzforchung. v. 36. n 2: p. 55 - 64. 1982.

HARTL, M.; HUMPF, H.U. Toxicity assessment of using the brine shrimp (Artemia salina) bioassay. Food and Chemical Toxicology. v. 38. p. 1097-1102. 2000.

HEIMBURGER, S.A.; BLEVING, D.S.; BOSTWICK, J.H., Kraft Mill Bleach Plant Effluents: Recent Developments Aimed at Decreasing their Environment Impact, Part 1, In: JAMELL, H. ed. Bleaching a Tappi press Anthology. n 779. Atlanta: p. 513 - 522. 1990.

MACKENZIE, L.D.; DAVID, A.C. Introduction to Environmental Engineering. 2 ed. McGrow-Hill. N.Y.: p. 645 - 722. 1991.

MOUNTEER, A.H. et al. Estudo da remoção biológica da DQO recalcitrante de efluente de branqueamento de polpa kraft de eucalipto. In: $35^{\circ}$ Congresso e exposição anual de celulose e papel. São Paulo/SP. 14 a 17 outubro, 2002.

PAIVA, T.C.B. Caracterização e Tratamento de Efluente de Branqueamento TCF de Indústria de Papel e Celulose. Unicamp. Campinas/São Paulo: 77 p. (Tese de Doutorado). 1999.

RIBEIRO, E. N., Avaliação da sensibilidade dos organismos utilizados em testes de toxicidade nos efluentes das indústrias de explosivos: seleção de uma bateria de testes na busca dos organismos ideais. EEL/USP. Lorena/SP. 168 p. (Tese de doutorado). 2008. 
SANTOS, L.F., Sistema de lodo ativado aplicado no tratamento de efluentes oriundos das etapas de fabricação de nitrocelulose. FAENQUIL. Lorena/SP. 103 p. (Dissertação de Mestrado). 2001.

Caracterização e tratamento de efluentes da fabricação de nitrocelulose. FAENQUIL. Lorena/SP. 102 p. (Tese de Doutorado). 2006.

SANT'ANNA, G. L. Jr. Tratamento biológico de efluentes: fundamentos e aplicações. Ed. Interciência. 2 ed. Rio de Janeiro/RJ. 418p. 2013.

TEIXEIRA, C. P. A. B.; JARDIM, W. F. Processos oxidativos avançados: conceitos teóricos, Caderno Temático 03. LQA/Unicamp. Campinas/SP. 2004. Disponível em http://lqa.iqm.unicamp.br/cadernos/caderno3.pdf. Acesso em: 31/03/2014.

TEMMING, H.; GRUNERT, H.; HUCKFELDT, H. Linters: Technical Information on Cotton Cellulose. English Translation of the 2 ed. Revised and Augmented German Edition. 1973. 